\title{
CARACTERÍSTICAS AGRONÔMICAS DE SORGO SOB NUTRIÇÃO FOLIAR DE MAGNÉSIO COM PRESENÇA E AUSÊNCIA DE SILÍCIO
}

\section{AGRONOMIC CHARACTERISTICS OF SORGHUM UNDER FOLIARY MAGNESIUM NUTRITION WITH PRESENCE AND ABSENCE OF SILICON}

Victor Hugo de Farias Guedes ${ }^{1}$; Renato de Mello Prado ${ }^{2}$; Antônio Carlos Buchelt ${ }^{3}$; Thayane Leonel Alves ${ }^{4}$; José Lucas Farias da Silva ${ }^{5}$

DOI: https://doi.org/10.31692/978-65-991061-4-9.123-126

\section{INTRODUÇÃO}

O magnésio $(\mathrm{Mg})$ exerce diversas funções nas plantas cultivadas, tais como: auxilia na fixação fotossintética do $\mathrm{CO}_{2}$, no carreamento no floema, atua na síntese proteica, na utilização dos fotoassimilados, participa do processos da fotofosforilação (HERMANS et al., 2005). Assim, vários processos fisiológicos e bioquímicos nas plantas podem ser alterados tanto pela deficiência quanto pelo excesso de Mg (MOREIRA et al. 2013, HERMANS et al. 2005). Porém acredita-se que os benefícios desse macronutriente pode ser maximizado com a interação com o silício (Si).

Há a hipótese que os benefícios do $\mathrm{Si}$, citadas anteriormente, poderiam melhorar a eficiência de uso de nutrientes, como o $\mathrm{Mg}$, o que levaria a uma redução na dose sem que haja perdas de produtividade. Porém, ainda são incipientes os estudos de interação do $\mathrm{Mg}$ e o Si em plantas de sorgo. Com isso, é necessário entender os mecanismos do Si na mitigação de deficiência de nutrientes e aumento de produtividade.

Assim, objetivou-se nesse trabalho avaliar as características morfológicas das plantas de sorgo com a aplicação foliar de concentrações magnésio com e sem Si na correção da deficiência moderada de $\mathrm{Mg}$ em plantas de sorgo.

\section{METODOLOGIA}

Com intuito de avaliar o efeito de concentrações de magnésio na ausência e presença de silício em plantas de sorgo cultivar DOW 1G244 foi realizado o experimento no período de

\footnotetext{
${ }^{1}$ Mestrando em Agronomia (Ciência do Solo), UNESP - Campus de Jaboticabal - Jaboticabal / São Paulo, Email: victorhguedes1@gmail.com

${ }^{2}$ Prof. Dr. Renato de Mello Prado, UNESP - Campus de Jaboticabal - Jaboticabal / São Paulo; Email:rmprado@fcav.unesp.br

${ }^{3}$ Doutorando em Agronomia (Produção Vegetal), UNESP - Campus de Jaboticabal - Jaboticabal / São Paulo, Email: antoniobuchett@hotmail.com

${ }^{4}$ Mestranda em Agronomia (Ciência do Solo), UNESP - Campus de Jaboticabal - Jaboticabal / São Paulo, Email: thayaneleonel@hotmail.com

${ }^{5}$ Mestrando em Agronomia (Ciência do Solo), UNESP - Campus de Jaboticabal - Jaboticabal / São Paulo, Email:fariaslucasf@gmail.com
} 
agosto a dezembro de 2018, em casa de vegetação na Universidade Estadual Paulista-UNESP, localizado no município de Jaboticabal, Brasil.

O delineamento experimental utilizado foi em blocos inteiramente casualizados, em esquema fatorial $3 \times 2$, sendo trêsconcentrações de magnésio $\left(0,17,0,34\right.$ e $\left.0,51 \mathrm{~g} \mathrm{~L}^{-1}\right)$ utilizando como fonte o quelato de magnésio (Quelmax - magnésio 6\%, quelatizado com EDTA) e duas concentrações de $\mathrm{Si}: 0,00$ e $0,50 \mathrm{~g} \mathrm{~L}^{-1}$ de $\mathrm{Si}$ utilizando como fonte o silicato de sódio e potássio alcalino estabilizado (107 $\mathrm{g} \mathrm{L}^{-1}$ de $\mathrm{Si}$ e $28,4 \mathrm{~g} \mathrm{~L}^{-1}$ de $\left.\mathrm{K}_{2} \mathrm{O}\right)$. Foram realizadas três pulverizações, em quatro repetições. Com a finalidade de se equilibrar as quantidades de potássio na aplicação dos tratamentos com e sem silício, foram realizadas aplicações foliares de cloreto de potássio.

A unidade experimental foi constituída de vaso de plástico com capacidade para $7 \mathrm{dm}^{3}$ (diâmetro superior: $16 \mathrm{~cm}$; diâmetro inferior: $11 \mathrm{~cm}$, altura: $33 \mathrm{~cm}$ ) preenchidos com $6 \mathrm{dm}^{3} \mathrm{de}$ areia textura média. As sementes de sorgo foram semeadas em bandeja contendo vermiculita. Após germinação foram transferidas três plantas para cada vaso. Com o desenvolvimento das mesmas realizou-se desbaste de modo a ficar uma planta por vaso. Depois de transplantadas, as plantas foram irrigadas com água deionizada.

Uma semana após, iniciou-se aplicação de solução nutritiva completa de Hoagland e Arnon (1950), de modo a manter 70\% da capacidade de campo, com pH entre 5,0 e 5,5 e com modificação na fonte de ferro, de Fe-EDTA para Fe-EDDHMA. Inicialmente, por um período de sete dias, a solução nutritiva foi aplicada a $10 \%$ da concentração. Após este período, a concentração da solução nutritiva foi aumentada para 20, 40 e $60 \%$ por uma semana em cada concentração e, transcorrido este período, para $70 \%$, a qual foi mantida até o final do período experimental. Uma vez por semana, foi realizada a drenagem do substrato com a aplicação de água deionizada para se evitar salinização. A partir do estádio V3 (plantas apresentando três folhas completamente desenvolvidas), foi retirado o magnésio da solução nutritiva para induzir a deficiência nas plantas.

As aplicações foliares foram realizadas em três estágios fenológicos: V4; V6, V8 e V10. A temperatura $\left({ }^{\circ} \mathrm{C}\right)$ e a umidade relativa do ar $(\%)$ foram medidas durante a primeira, segunda e terceira pulverizações foliares obtendo-se os seguintes valores: 23,5 e 59, 20 e 75, 20,1 e 68 e 18,9 e 99 , respectivamente.

A calda de pulverização foi preparada utilizado o Sorbitol como adjuvante, sendo o valor $\mathrm{pH}$ ajustado entre 6,9 e 7,0. A aplicação foliar foi realizada imediatamente após o preparo da calda com pulverizador manual, visando à cobertura total da parte aérea. O volume de calda aplicado variou de acordo com o tamanho das plantas, sendo aplicados 3,0; 4,0 e 5,0 
$\mathrm{mL}$ da solução, para a primeira, segunda e terceira pulverizações, respectivamente. Durante as aplicações foliares, a superfície do substrato foi coberta com papel toalha para evitar escorrimento da solução pulverizada para o substrato, de modo a se garantir que a absorção das soluções fosse totalmente via foliar.

Após a maturação fisiológica foram avaliadas as seguintes características: altura de planta, número de folhas, tamanho de panícula, diâmetro de colmo. A altura de planta e tamanho de panícula foram determinadas por uma régua graduada, o número de folha foi pela contagem e o diâmetro de colmo foi utilizado um paquímetro digital $150 \mathrm{~mm} / 6$ " $316119 \mathrm{mtx}$.

Os dados obtidos foram submetidos à análise de variância pelo teste $\mathrm{F}$ e, quando significativo, ao teste de comparação t de Student (LSD), a 5\% de probabilidade, utilizando-se o software AgroEstat® (Barbosa; Maldonado Júnior, 2010).

\section{RESULTADOS E DISCUSSÃO}

Os resultados obtidos com as pulverizações foliares de magnésio e silício na cultura do sorgo não apresentaram efeito de interação entre os elementos para nenhuma variável avaliada, portanto, a discussão será realizada apenas em relação aos efeitos dos elementos separadamente nos parâmetros avaliados.

Em relação à altura de planta, número de folhas, tamanho de panículas e diâmetro de colmo, somente a altura de planta foi influenciada pela a aplicação do magnésio o mesmo não ocorreu com a aplicação do silício (Tabela 1). Os maiores valores em relação à altura das plantas foram observados nas maiores concentrações de magnésio 0,34 e 0,51 g L $\mathrm{L}^{-1}$ com valores respectivos de 75,00 e 78,25 cm. Plantas fertilizadas com o Mg em níveis adequados tem funções fisiológicas maximizadas, tais como, síntese proteica e melhor utilização dos fotoassimilados (HERMANS et al., 2005), isso favoreceu o melhor desempenho em relação à altura das plantas que receberam as maiores concentrações de $\mathrm{Mg}$ via foliar.

Flores et al. (2018) avaliando o efeito da aplicação foliar do Si na qualidade fisiológica, produção de biomassa e acúmulo de silício em sorgo observaram que o suprimento de Si via foliar não afetou a taxa de crescimento, resultado que corrobora com o presente trabalho.

Tabela 1: Altura de planta (AP), número de folhas (NF), tamanho de panículas (TP) e diâmetro de colmo (DC) na cultura de sorgo submetida à aplicação foliar de concentrações de magnésio $(\mathrm{Mg})$ e silício $(\mathrm{Si})$.

\begin{tabular}{|l|l|l|l|l|}
\hline \multirow{2}{*}{ Tratamentos } & AP & NF & TP & DC \\
\cline { 2 - 5 } & $(\mathbf{c m})$ & - & $(\mathbf{c m})$ & $(\mathbf{m m})$ \\
\hline $\begin{array}{l}\text { Concentrações de } \\
\text { Mg }\left(\mathbf{g ~ L}^{-1}\right)\end{array}$ & $\mathbf{0 , 0 0 2} *$ & $\mathbf{0 , 9 7 5}^{\text {ns }}$ & $\mathbf{0 , 4 7 2}$ & \\
\hline 0,17 & $70,50 \mathrm{~b}$ & 6,87 & 23,50 & 13,25 \\
\hline
\end{tabular}




\begin{tabular}{|c|c|c|c|c|}
\hline 0,34 & $75,00 \mathrm{a}$ & 6,87 & 23,00 & 12,75 \\
\hline 0,51 & $78,25 \mathrm{a}$ & 7,00 & 21,75 & 12,62 \\
\hline $\begin{array}{l}\text { Concentrações de } \\
\mathrm{Si}\left(\mathrm{g} \mathrm{L} \mathrm{L}^{-1}\right)\end{array}$ & $0,104^{\mathrm{ns}}$ & $\mathbf{0 , 5 3 5 ^ { \mathrm { ns } }}$ & $0,272^{\text {ns }}$ & $0,715^{\mathrm{ns}}$ \\
\hline 0,00 & 73,25 & 7,08 & 23,42 & 13,00 \\
\hline 0,50 & 75,92 & 6,75 & 22,08 & 12,75 \\
\hline CV(\%) & 5,11 & 18,66 & 12,67 & 12,85 \\
\hline Média & 74,58 & 6,92 & 22,75 & 12,87 \\
\hline MgxSi & $0,72^{\mathrm{ns}}$ & $0,727^{\mathrm{ns}}$ & $0,729^{n s}$ & $0,212^{\text {ns }}$ \\
\hline
\end{tabular}

Legenda: ns e *- não significativo e significativo a $5 \%$ de probabilidade pelo teste $\mathrm{F}$. Letras iguais não diferem pelo teste $\mathrm{t}$ de Student a 5\% de significância.

Fonte: Própria (2019)

\section{CONCLUSÕES}

O fornecimento de quelato de magnésio via pulverização foliar aumenta a altura de planta, massa seca de 500 grãos e o acúmulo do elemento na parte aérea na cultura do sorgo.

\section{REFERÊNCIAS}

BARBOSA, J. C.; MALDONADO JÚNIOR, W. AgroEstat: sistema para análises estatísticas de ensaios agronômicos.Jaboticabal: Faculdade de Ciências Agrárias e Veterinárias, Unesp, 2010 .

FLORES, R. A., ARRUDA, E. M., DAMIN, V., JUNIOR, J. P. S., MARANHAO, D. D. C., CORREIA, M. A. R., \& DE MELLO PRADO, R. PhysiologicalqualityanddrymassproductionofSorghum bicolor followingsilicon (Si) foliar application. AustralianJournalofCrop Science, v. 12, n. 4, p. 631, 2018.

HERMANS, C., BOURGIS, F., FAUCHER, M., DELROT, S., STRASSER, R. J., VERBRUGGEN, N. 2005. Magnesiumdeficiency in sugar beetalters sugar partitioningandphloemloading in young mature leaves. Planta, 220, 541-549.

HOAGLAND, D. R.; ARNON, D. I. The waterculturemethod for growingplantswithoutSoil.Calif. Agr. Exp. STA. Cir, 347p., 1950.

MOREIRA, W. R., RESENDE, R. S., RODRIGUES, F. A., ANDRADE, C. C. L., NASCIMENTO, C. W. A. (2013). Influência do magnésio na resistência do arroz à mancha parda. Bragantia, 72(2), 154-161. 